\title{
Effect of a designed nursing protocol on nurse's knowledge \& practice regarding Coronary Artery Bypass Graft surgery.
}

\author{
Ghada H. Ahmed, Zienab A. Mohammad, Mahmoud K. Abd-Elateef \& Hala M. Ghanem. \\ Assistant lecture of Medical-Surgical Nursing, Faculty of Nursing, Assiut University, Egypt \\ Professor of Medical-Surgical Nursing, Faculty of Nursing, Assiut University, Egypt \\ Assistant Professor of Cardiothoracic surgery, Faculty of Medicin, Assiut University, Egypt \\ Assistant Professor of Medical-Surgical Nursing, Faculty of Nursing, AssiutUniversity, Egypt.
}

\begin{abstract}
Background: The aim of the study was : To assess nurses' knowledge and practice regarding patients undergoing coronary artery bypass graft surgery, to design nursing care protocol for nurses, and to evaluate the effect of implementing the designed nursing protocol on nurse's knowledge and practice. Three hypotheses were formulated: (1) the post mean knowledge scores of nurses who will expose to designed nursing protocol will be higher than their pre mean knowledge scores. (2) The post mean practice score of nurses who will expose to designed nursing protocol will be higher than their pre mean practice scores. (3) A positive relationship will exist between knowledge and practice score obtained by nurses receiving the designed nursing protocol. Research design: Quasiexperimental research design was utilized in this study. Tools: Three tools were utilized for data collection were a) structured interview sheet. b) Observation checklist sheet. c) Construction of designed nursing protocol. Results The first and the second hypotheses were supported as a good improvement in the mean knowledge \& practice scores. Conclusion: implementing of designed nursing protocol showed a significant improvement in nurses knowledge and practice. Recommendations: Nurses are in need for in-service training programs and refreshing courses to improve their knowledge.
\end{abstract}

\section{Key words: Designed Nursing Protocol, Nurse's Knowledge \& Practice \& Coronary Artery Bypass} Graft Surgery.

\section{Introduction}

Coronary heart disease (CHD) affects 16.8 million people in the United States and causes more than 607,000 deaths annually. CHD is caused by impaired blood flow to the myocardium. Accumulation of atherosclerotic plaque in the coronary artery is the usual cause. CHD may be asymptomatic, or may lead to angina pectoris, acute coronary syndrome, myocardial infarction, dysrhythmias, heart failure, and even sudden death (Mohward Islam \& Majumder, 2013). According to present trends in the United States, half of healthy 40-year-old males will develop coronary artery disease(CAD) in the future, and one in three healthy 40-year-old women. It is the most common reason for death of men and women over 20 years of age in the United States (Heart Foundation of New Zealand, 2013).

CAD accounts for nearly three-quarters of all deaths from cardiovascular disease. It is estimated that 571,000 cardiac bypass surgeries are performed on 355,000 people annually in the USA. Of the people who undergo bypass surgery, 238,000 are men, 117,000 are women, and 27,000 are over 65 years of age (American Heart Association, 2005).

Coronary Artery Bypass Grafting (CABG) is a surgical procedure in which a blood vessel is grafted to the occluded coronary artery so that blood can flow beyond the occlusion. The CABG procedure is indicated for patients with three vessel disease, poor left ventricular ejection fractions $(\mathrm{LVEF})>35 \%$, or significant disease in the left main coronary artery. It may also be indicated as an emergent "rescue" procedure in patients whose coronary artery dissects or fractures during an attempted percutaneous procedure (Thoralf, 2010).

The vessel most commonly used for CABG is the greater saphenous vein, followed by the lesser saphenous vein. Cephalic and basilic veins are used also. The saphenous vein graft is usually harvested by the physician assistant and can be taken through a long skin incision or recently by the endoscope (Mishra et al., 2006). The right and left internal mammary arteries (RIML, and LIML) and, occasionally, radial arteries are also used for CABG. Arterial grafts are preferred to vein grafts because they do not develop atherosclerotic changes as quickly and remain patent longer. The gastroepiploic artery (located along the greater curvature of the stomach) may also be used, although it does not respond as well when used as a graft. The gastroepiploic artery graft seems to have a better 
patency rate than the saphenous vein graft but a somewhat poorer patency rate than the left internal mammary artery (Suma, 2013).

Any medical procedure has possible risks and complications. The most common risks in bypass surgery include: bleeding, stroke, and myocardial infarction. Other postoperative complications to consider after CABG include cardiac tamponade, renal failure, respiratory failure, dysrhythmias, wound infection and both pericardial and pleural effusion (Osborn et al., 2010).

The nurse's role is to provide quality patient care appropriate to the needs of the individual patient. Surgery is a unique "human" experience that can be described as a planned alteration that encompasses three phases: preoperative, intra operative and postoperative phase. The nursing activities associated with preoperative phase include physical and psychological preparation of patient before surgery

\section{(American Heart Association, 2006).}

The nursing activities related to intraoperative phase include a variety of specialized procedures designed to created and maintain a safe, therapeutic environment for the patient and the health care personnel providing the care. The nursing activities related to post operative phase include cardiac monitoring, monitoring of hemodynamic status, monitoring chest tube drainage, urine output, and close observation of wounds for any signs of infection (Kaplow and Hardin, 2007).

\section{Aim of the study}

The aim of this study was covered in three folds:

- To assess nurses' knowledge and practice regarding patients undergoing coronary artery bypass graft surgery,

- To design nursing care protocol for nurses working with coronary artery bypass graft surgery,

- To evaluate the effect of implementing the designed nursing protocol on nurse's knowledge and practice regarding coronary artery bypass graft surgery patients.

\section{Hypothesis}

To fulfill the aim of the study, the following research hypothesis were formulated:

- The post mean knowledge scores of nurses who will be exposed to designed nursing protocol will be higher than their pre mean knowledge scores.

- The post mean practice score of nurses who will be exposed to designed nursing protocol will be higher than their pre mean practice scores.

- A positive relationship will exist between knowledge and practice score obtained by nurses receiving the designed nursing protocol.

\section{Subjects \& Method}

\section{Research design}

Quasi-experimental research design has been utilized in this study.

\section{Setting of the study}

The study was conducted in cardiothoracic surgery department, intensive care unit, and operating room at Assiut University Hospital.

\section{Study subjects}

A convenience sample of all available nurses are working in selected setting (about 38 nurses); (10) nurses working in cardiothoracic surgery department, (23) nurses working in intensive care unit, and (5) nurses working in operating room and who are willing to participate in the study.

\section{Tools of data collection}

- Structured interview sheet (pre / post tests), which was developed in a simple clear Arabic language by the researchers based on literature review and experts' opinions in the light of relevant references to assess nurses' knowledge regarding patients undergoing coronary artery bypass grafting. It included the following parts:

- The first part: related to socio-demographic characteristics of the study subjects age, marital status, qualification, years of experience, and attendances of training program.

- The second part: related to nurses' knowledge about heart and coronary arteries: definition of heart, coronary arteries, coronary artery bypass grafting, indications of coronary artery bypass grafting, types of coronary arteries, layers of coronary arteries, and types of coronary artery bypass grafting.

- The third part: related to nurses' knowledge about nursing care for patient undergoing coronary artery bypass grafting.

- Scoring system: The total score for all items was 150. Each right answer was given two score. Those who obtained less than $50 \%$ were considered having unsatisfactory level of knowledge. While those who obtained from $(50 \%-70 \%)$ or above $70 \%$ were considered having satisfactory level of knowledge.

Observation checklist sheet (pre / post tests): It was developed and filled by the researchers to assess expected complications that might develop among patients of coronary artery bypass grafting. It included the following parts:

- The first part: related to pre-operative procedures: it was included vital signs, deep breathing and coughing exercises and leg exercises.

- The second part: related to intra operative procedures: it was included perform surgical hand antisepsis. 
- The third part: it was included neurological assessment (verbal and motor response), vital signs, arterial blood gases, electrocardiography, and instructions prior to discharge.

Scoring system: Each item was observed, categorized, and scored as follow: 2 for each step that done correct (correctly, in time and with the required frequency) and 1 for each step done incorrect (incorrectly, not in time and without the required frequency) and zero for step that not done. Inapplicable means that the nurses were not able to apply the principles of the standard due to shortage in supplies and equipment, not due to shortage or negligence from the nurses. Those who less than $(50 \%)$ were considered having inadequate level. Above $(50 \%)$ were considered having adequate level. Construction of designed nursing protocol: It was developed by the researcher based on nurses needs assessment, literature review, researcher experience and opinions of the medical and nursing expertise. The teaching booklet was revised and modified based on the expertise comments, it was written in Arabic using simple language with illustrations.

\section{Content validity}

It was established by panel of 5 expertises who reviewed the instruments for clarity, relevance, comprehensiveness, understanding, applicability and easiness for administrative minor modifications were required. The content validity of this tool was checked by expert professors in fields of medicine and nursing and correction was carried out accordingly.

Ethical considerations and human rights: An official permission to conduct the study was obtained by the researcher from the head of the cardiothoracic surgery, post operative intensive care unit at Assiut university hospital as well as from head nurses of each unit. Nurses were informed of the purpose and nature of the study. The investigator emphasized that the participation is voluntary and confidentiality and anonymity of the subjects will be assured through coding all of data.

Tools testing and pilot study: A pilot study was implemented on $10 \%$ of the total study subjects to test the tools. Analyses of the pilot study revealed that minimal modifications are required. These modifications were done and the subjects were not excluded from the actual study.

\section{Procedures}

- Data were collected at Cardiothoracic department, Operating room unit, and Post operative intensive care unit at Assiut University Hospital during the period from 31/1/2012 to 20/8/2014.

- The tools filled through interviewing. The purpose of the study was explained to the nurses prior to answering the questions. The study was carried out at morning, and after noon shifts.

- At initial interview the researcher introduce her self to initiate line of communication, explain the nature \& purpose of the developed nursing care standards and fill out the structured interview sheet (tool I) to assess nurse's knowledge pre implementation of nursing care protocol and the researcher fill out the observation checklist sheet (tool II) to assess nurse's practice pre implementation of nursing care standards.

- The researcher scheduled with them the teaching sessions for both theory and practice and the nurses were divided into small groups, each group contains 3-4 nurses. Teaching has been implemented for nurses in terms of sessions and teaching on the spot during their official working hours. There were a total of 10 sessions. The duration of each session was 30-45 minutes, including 10 minutes for discussion and feedback.

- The effect of the designed nursing care protocol was reached through comparing level of nurse's knowledge and practice pre and post implementing of nursing care protocol has been evaluated by the researcher through filling the study tool (I,II). 


\section{Results}

Table (1): Distribution of socio-demographic characteristics of the studied nurses $(n=38)$.

\begin{tabular}{|c|c|c|}
\hline \multirow{2}{*}{ Characteristics } & \multicolumn{2}{|c|}{ Frequency $(\mathrm{N}=38)$} \\
\hline & No. & $\%$ \\
\hline $\begin{array}{l}\text { Age } \\
\quad<20 \text { year } \\
20: 40 \text { year } \\
>40 \text { year }\end{array}$ & $\begin{array}{c}3 \\
30 \\
5\end{array}$ & $\begin{array}{r}7.89 \\
78.94 \\
13.15 \\
\end{array}$ \\
\hline Mean \pm SD & $24.67 \pm 3.69$ & \\
\hline $\begin{array}{ll}\text { Sex } & \\
& \text { Male } \\
& \text { Female }\end{array}$ & $\begin{array}{c}4 \\
34\end{array}$ & $\begin{array}{l}10.52 \\
89.47\end{array}$ \\
\hline $\begin{array}{c}\text { Marital status } \\
\text { Single } \\
\text { Married } \\
\end{array}$ & $\begin{array}{l}12 \\
26 \\
\end{array}$ & $\begin{array}{l}31.57 \\
68.42 \\
\end{array}$ \\
\hline $\begin{array}{l}\text { Education: } \\
\text { Diploma Nurse } \\
\text { Technical Nurse } \\
\text { Baccalaureate Nurse } \\
\end{array}$ & $\begin{array}{c}30 \\
7 \\
1 \\
\end{array}$ & $\begin{array}{c}78.94 \\
18.42 \\
2.63 \\
\end{array}$ \\
\hline $\begin{array}{l}\text { Experience: } \\
<5 \text { years } \\
5: 10 \text { years } \\
>10 \text { years }\end{array}$ & $\begin{array}{c}9 \\
26 \\
3\end{array}$ & $\begin{array}{c}23.68 \\
68.42 \\
7.89\end{array}$ \\
\hline Mean \pm SD & & \\
\hline $\begin{array}{l}\text { Previously Attended of training courses related to } \\
\text { coronary artery bypass graft surgery: } \\
\text { Yes } \\
\text { No }\end{array}$ & $\begin{array}{l}13 \\
25\end{array}$ & $\begin{array}{l}34.21 \\
65.78\end{array}$ \\
\hline
\end{tabular}

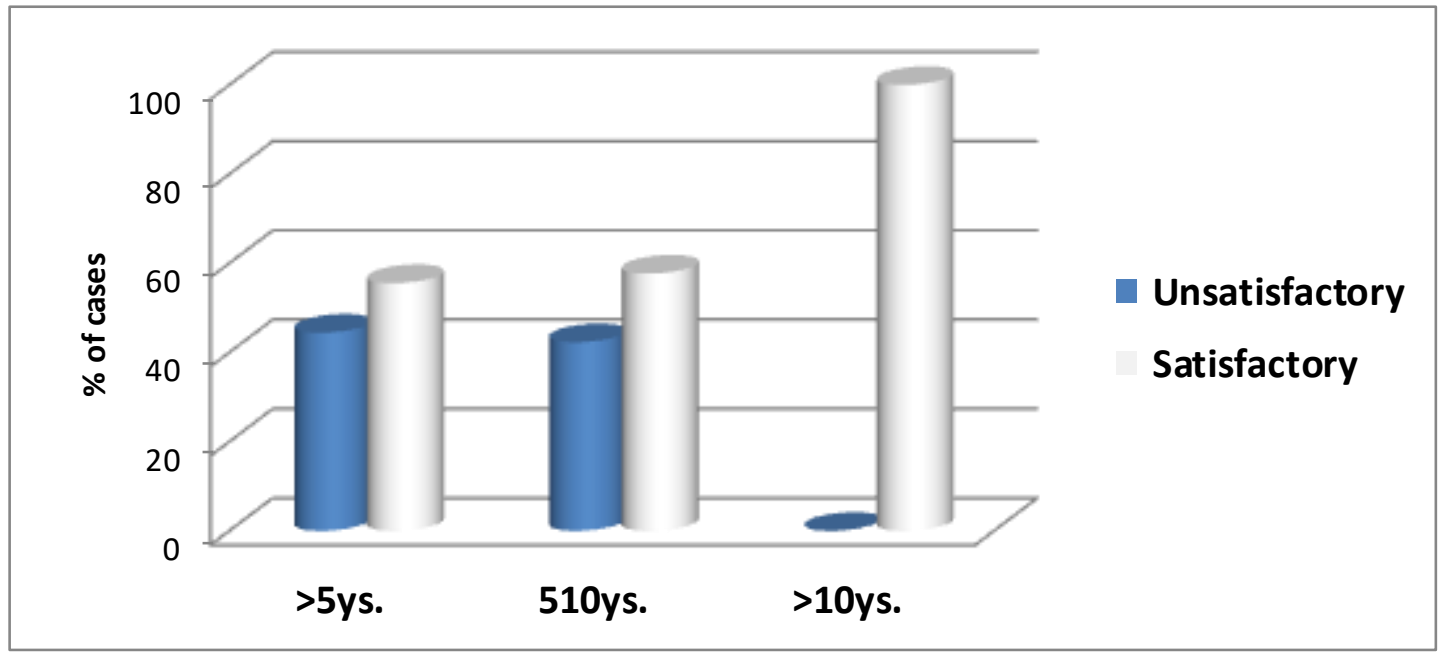

Figure (1): Relationship between nurse's knowledge score and their experience post implementing of designed nursing care protocol. 


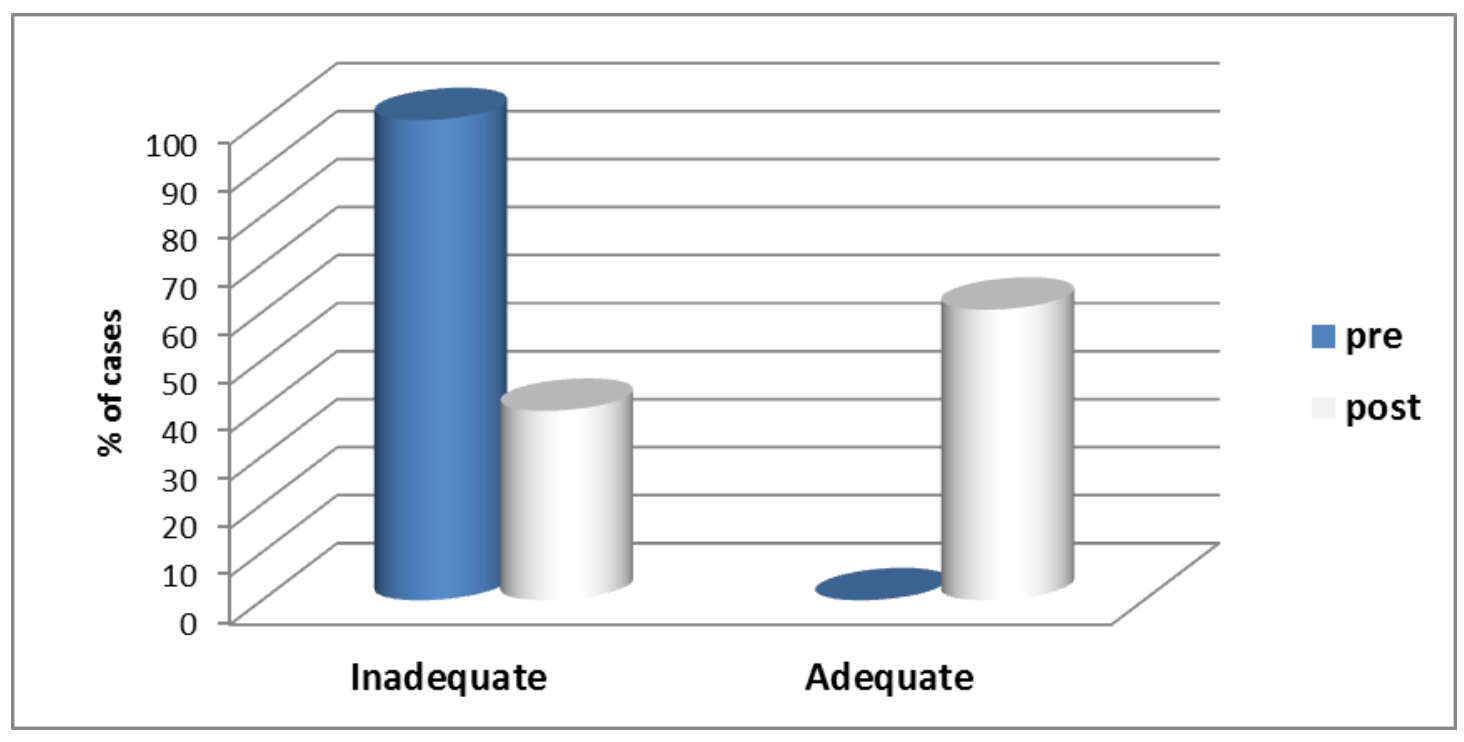

Figure (2): Frequency distribution of the level of nurses` practice as regard pre and post implementing of designed nursing care protocol for patient undergoing coronary artery bypass grafting $(n=38)$.

Table (2): Total mean knowledge scores obtained by nurses pre and post implementing designed nursing care protocol for patient undergoing coronary artery bypass grafting $(n=38)$.

\begin{tabular}{|l|c|c|}
\hline \multicolumn{1}{|c|}{ Knowledge Items } & Mean \pm SD & p-Value \\
\hline $\begin{array}{l}\text { Knowledge about anatomy of heart and coronary artery, } \\
\text { coronary artery bypass grafting: } \\
\text { (Maximum score = 30) }\end{array}$ & & \\
$\quad \begin{array}{l}\text { Pre-test } \\
\text { post-test }\end{array}$ & $11.62 \pm 2.79$ & $* * *$ \\
\hline $\begin{array}{l}\text { Knowledge about nursing care for patients undergoing } \\
\text { coronary artery bypass grafting: } \\
\text { (Maximum score = 120) }\end{array}$ & & 0.0001 \\
$\quad \begin{array}{l}\text { Pre-test } \\
\text { post-test }\end{array}$ & $21.70 \pm 4.57$ & \\
\hline $\begin{array}{l}\text { Total score (Maximum score = 150) } \\
\text { Pre-test } \\
\text { post-test }\end{array}$ & $57.43 \pm 12.11$ & $* .72$ \\
\hline
\end{tabular}

***: $\quad$ Highly significant 
Table (3): Frequency distribution of the level of nurses` knowledge as regard pre and post implementing of designed nursing care protocol $(n=38)$.

\begin{tabular}{|l|c|c|c|c|c|}
\hline \multirow{2}{*}{ Level of nurse's knowledge } & \multicolumn{2}{|c|}{ Pre test } & \multicolumn{2}{|c|}{ Post test } & \multirow{2}{*}{ p-Value } \\
\cline { 2 - 6 } & No & \% & No & \% & \\
\hline Satisfactory & - & - & 23 & 60.52 & $* *$ \\
\hline Unsatisfactory & 38 & 100.0 & 15 & 39.47 & 0.001 \\
\hline
\end{tabular}

**Moderate significant

Table (4): Total mean practice scores obtained by nurses pre and post implementing designed nursing care protocol for patient undergoing coronary artery bypass grafting $(n=38)$.

\begin{tabular}{|c|c|c|c|c|}
\hline \multirow{2}{*}{ Nurses` practice } & \multirow{2}{*}{ Total score } & \multicolumn{2}{|c|}{ Mean + SD } & \multirow[t]{2}{*}{ P-value } \\
\hline & & Pre test & Post test & \\
\hline Pre operative preparation & 62 & $10.76 \pm 0.30$ & $47.62 \pm 5.63$ & $\mathrm{P}<0.0001 * * *$ \\
\hline Infection control measures & 112 & $12.32 \pm 2.99$ & $48.50 \pm 11.33$ & $\mathrm{P}<0.0001 * * *$ \\
\hline Intraoperative nursing care & 34 & $9.75 \pm 1.34$ & $18.09 \pm 1.00$ & $\mathrm{P}<0.0001 * * *$ \\
\hline Immediate postoperative care & 80 & $17.32 \pm 0.56$ & $65.61 \pm 9.05$ & $\mathrm{P}<0.0001 * * *$ \\
\hline $\begin{array}{l}\text { Continuous monitoring and recording } \\
\text { are following post surgery }\end{array}$ & 330 & $132.3 \pm 1.22$ & $265.15 \pm 79.59$ & $\mathrm{P}<0.0001 * * *$ \\
\hline Educate the patient before discharge & 44 & $13.07 \pm 1.21$ & $26.01 \pm 11.62$ & $\mathrm{P}<0.0001 * * *$ \\
\hline $\begin{array}{l}\text { Safety measures for each patient } \\
\text { during transportation from operating } \\
\text { room to intensive care unit }\end{array}$ & 220 & $93.07 \pm 1.21$ & $186.01 \pm 11.62$ & $\mathrm{P}<0.0001 * * *$ \\
\hline $\begin{array}{l}\text { All staff (health team) follow ethics } \\
\text { and patients right in the } \\
\text { cardiothoracic department, operating } \\
\text { room, and intensive care unit }\end{array}$ & 10 & $2.98 \pm 0.93$ & $6.43 \pm 1.33$ & $\mathrm{P}<0.0001 * * *$ \\
\hline Nurses are follow professionalism & 18 & $4.06 \pm 1.8$ & $9.76 \pm 2.01$ & $\mathrm{P}<0.0001 * * *$ \\
\hline Total practice scores $(910)$ & & $307.6 \pm 10.4$ & $690.83 \pm 122.8$ & $\mathrm{P}<0.0001 * * *$ \\
\hline
\end{tabular}

***: Highly significant

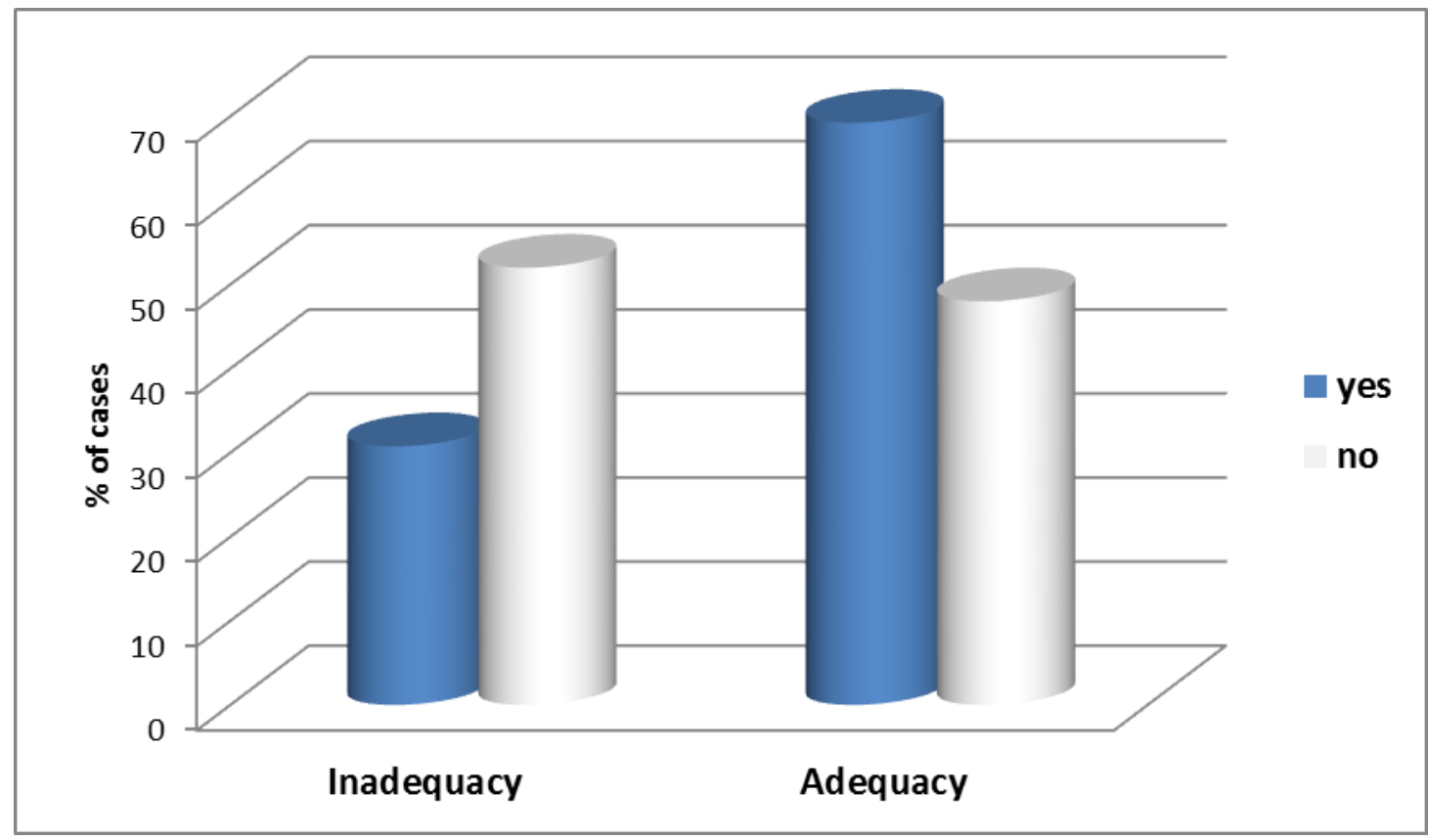

Figure (3): Relationship between total nurse's practice score $\&$ attending previous training program pre implementing nursing care protocol $(n=38)$. 
Table (1): This table clarified that; the majority of the nurses $(78.94 \%)$ their age ranged from 20 to 40years and have diploma degree. $(68.42 \%)$ of them were married, their experiences were ranged from 5 to 10years $(68.42 \%)$ with mean duration of $7.83 \pm 2.51$ years. The majority of the nurses $(65.78 \%)$ did not attend any training courses related to coronary artery bypass graft surgery.

Figure (1): This figure shows that; there was significant difference between nurse's knowledge scores and their years of experience, it was found that, less than half of nurses of experience ranged from 5-10 years had satisfactory level of knowledge. The nurses who had experience more than 10 years had satisfactory level of knowledge post implementing nursing care protocol with $p$ value $<0.02$.

Figure (2): This figure reveals that; more than half of nurses had adequate practice in post implementing of designed nursing care protocol $(60.52 \%)$ with $\mathrm{P}<0.0001$.

Table (2): This table revealed that; the mean scores for total knowledge was low pre implementing of designed nursing care protocol (11.62 \pm 2.79 , $24.10 \pm 6.72,35.72 \pm 9.51$ respectively) and there was an noticeable improvement in the mean knowledge scores post the implementation of designed nursing care protocol $(21.70 \pm 4.57,57.43 \pm 12.11,79.13 \pm 16.68$ respectively).

Table (3): This table demonstrates that; the majority of nurses had satisfactory level of knowledge in post implementing designed nursing care protocol $(60.52 \%)$ with $(\mathrm{P}<0.0001)$.

Table (4): This table shows that; the mean scores for total practice was low pre implementing of the designed nursing care protocol $(10.76 \pm 0.30$, $12.32 \pm 2.99, \quad 9.75 \pm 1.34, \quad 17.32 \pm 0.56, \quad 132.3 \pm 1.22$, $13.07 \pm 1.21,93.07 \pm 1.21,2.98 \pm 0.93$, and $4.06 \pm 1.8$ respectively). However, a good improvement in the mean practice scores post the implementation of nursing care protocol $(47.62 \pm 5.63,48.50 \pm 11.33$, $18.09 \pm 1.00, \quad 65.61 \pm 9.05, \quad 265.15 \pm 79.59$, $26.01 \pm 11.62, \quad 186.01 \pm 11.62, \quad 6.43 \pm 1.33$, and $9.76 \pm 2.01$ respectively).

Figure (3): This figure shows that; there was a highly statistical significant difference regarding $(\mathrm{P}<0.0001)$ total nurse's practice score and attending previous training program of nurses about nursing care for patient undergoing coronary artery bypass grafting.

\section{Discussion}

Cardiothoracic surgery nurse should be qualified enough to care for patients because those patients need special nursing care; standard nursing care to improve their conditions and to help in preventing or reducing potential postoperative complications. Nurses should develop their own standards of care and the profession should agree on acceptable levels of excellence. Nurses are planned, systematic and focused on mutually agreed goals in which standards of care influence nursing practice, education and management (Huston, 2003).

The results of the present study showed; that the majority of nurses were aged from 20 - 40 years. The majority of nurses were female and nursing diploma was the highest proportion, more than half of them, their experiences were ranged from 5 to 10 years and the majority of them have no in service training courses related to coronary artery bypass graft surgery.

Ahmed, (2013); in the same line with the current study findings conducted a study in neurosurgery department at Assiut University Hospital entitled "Developing nursing care standards for patients post discectomy at Assiut University Hospital". Reported that, the majority of nurses were female, nursing diploma was the highest proportion, less than half of them have an experience more than ten years and all of them have no in service training courses related to standards of nursing care for patients with discectomy.

As regard nurse's knowledge, the current study showed that, pre implementing nursing care protocol showed unsatisfactory level of nurse's knowledge about anatomy of heart, coronary arteries and nursing care for patients undergoing coronary artery bypass graft surgery, which reflects the lack in their scientific preparation. Post implementation of nursing care protocol showed an improvement in the nurses' level of knowledge regarding the care offered to coronary artery bypass graft surgery patients. The findings indicate that a good improvement in the mean knowledge scores after implementation of nursing care protocol.

So, we can conclude from the data collected and analysis in the present study that all studied nurses weren't properly prepared prior to their working and/or dealing with such coronary artery bypass graft surgery patients and really they got their experience while being there, working and managing the patients in the real life emergency situations.

In this respect, Change, (2006); mentioned that nurses must be able to expand their knowledge of this area through ongoing education, Journal, and seminars. Consequently, teaching programs for nursing staff constitute an important part. These programs are urgently designed to assess nursing 
staff in developing and enhancing the skills needed to provide high standards of care to their patients.

The current study revealed a great improvement in the level of nurse's practice post implementing nursing care protocol in all items. This has been concluded by the presence of significant differences between results of pre and post implementing nursing care protocol. This finding indicated that skills can be easily improved, especially if linked with their relevant scientific base of knowledge.

In this respect, Sherwood, (1996); reported an improvement in nurses' practice after the attendance at continuing nursing education sessions. Research findings indicated that continued nursing education programs increase both knowledge and performance and can also improve attitudes. As well, Abd-Ala, (2000); documented that the inservice training program has a beneficial effect in improving the nurses' knowledge and skills. They also recommended that educational programs should be organized according to the needs of nurses with continuous evaluation.

\section{Conclusion}

In the light of the current study it can be concluded that, Implementation of designed nursing care protocol for patients with coronary artery bypass grafting shows a significant improvement in nurses knowledge and practice.

\section{Recommendations}

- Continued nursing education and inservice training programs on cardiothoracic department and intensive care unit should be well organized within Assiut University Hospital and equipped with the necessary educational facilities and materials necessary to upgrade the knowledge and skills of practicing nurses, which will be reflected on better outcome and service for inpatients.

- Nurses should add to their routine obligations the regular reading of up-to-date references (periodicals, textbooks, etc.). They should always be encouraged to attend scientific meetings and conferences to keep pace with the rapidly growing wealth of knowledge and practice necessary for proper nursing service.

- Newly employed nurses in cardiothoracic department and intensive care unit are required to successfully complete a test of basic knowledge and skills before assuming independent responsibility for patient care.

- Replication of the study on larger random sample acquired from different geographical areas in Egypt to figure out the main aspect of this problem, so further research studies are highly recommendation to gather in depth knowledge about nursing care for patients undergoing coronary artery bypass grafting.

\section{References}

1. Mohwarul Islam, A., \& Majumder, A., (2013): Coronary artery disease in Bangladeshi: Indian Heart J.Jul 2013; 65(4): 424-435.

2. Abd-Alla M., (2000): Assuring quality care through a managerial inservice training program for head nurses working in Assiut University Hospital. DNS thesis of nursing service administration. Assiut University. Thesis published2000.

3. AHA Statistical Fact Sheet 2005 Update. (2005): American Heart Association. Retrieved May 18, 2005, fromwww.americanheart.org

4. Ahmed, A.., (2013) : Developing nursing care standards for patient with discectomy at Assuit University Hospital thesis Submitted for Partial Fulfilment of the Requirement of the Master Degree in Medical Surgical Nursing, faculty of nursing Assiut. Thesis not published.

5. American Heart Association (2006): Risk factors and Coronary Heart Disease. Accessed March 27. P.p427-431.

6. Change, J., (2006): Principles of Microsurgery. Published in the internet by e Medicine: http://www.emedicine.com/plastic/topic262.html

7. Hawkes A., Nowak M., Bidstrup B., \& Speare R., (2006): Outcomes of coronary artery bypass graft surgery. Vasc Health Risk Manag. December; 2(4): 477-484.

8. Heart Foundation of New Zealand (2013): General Statistics. Heart Foundation of New Zealand,Auckland.

http://www.heartfoundation.org.nz/know-thefacts/statistics.

9. Huston, B., (2003): Quality health care in an area of diminished resources, Journal of Nursing Care Quality, 18(4), pp. 295- 301.

10. Kaplow R., \& Hardin S., (2007): Critical Care Nursing Synergy for optimal outcomes. Jones \& Bartlett Publishers Sudbury, Massachusetts Boston Toronto. London Singapore. P.P (121124, 229-235).

11. Mishra Y., Wasir H., Sharma K., Mehta Y., Trehan N., (2006): Totally Endoscopic Coronary Artery Bypass Surgery. Asian Cardiovasc Thorac Ann. 2006;14:447-451.

12. Osborn, K., Wraa, C., Watson, A., (2010): Medical Surgical Nursing: Preparation for practice, 1 st ed. Chapter 40, Pearson, P 1211. 
13. Sherwood G., (1996): Nursing Administrator Perception of the impact of continuing nursing education in underserved areas. J Cont Edu Nurs; 27 (3): $129-33$.

14. Suma H., (2013): Gastroepiploic artery graft in coronary artery bypass grafting, Suma Heart Clinic, Tokyo, Japan, Corresponding to: Hisayoshi Suma, MD. SUMA SQUARE, Hillside West B-002, 13-4 Hachiyamacho, Shibuya-ku, Tokyo 150-0035, Japan. Email: suma@sumaheart.jp. Vol 2, No 4 (July 2013

15. Thoralf M., (2010): New Study Shows Superiority of CABG over Drug Eluting Stents, retrieved

from http://www.sts.org/sections/patientinformation/a dultcardiacsurgery/cabg/ 